\title{
Newborn or Infant Finding
}

National Cancer Institute

\section{Source}

National Cancer Institute. Newborn or Infant Finding. NCI Thesaurus. Code C118807.

Clinical, laboratory or molecular evidence, or absence of evidence of disease in a neonate or infant. 